\title{
Enabling Flexibility Through Wholesale Market Changes - A European Case Study
}

\author{
Ben Bowler ${ }^{1(\bowtie)}$, Marcus Asprou ${ }^{2}$, Balint Hartmann ${ }^{3}$, \\ Peyman Mazidi ${ }^{4}$, and Elias Kyriakides ${ }^{2}$ \\ ${ }^{1}$ EMAX, Brussels, Belgium \\ ben.bowler@emaxgroup.eu \\ ${ }^{2}$ University of Cyprus, Nicosia, Cyprus \\ ${ }^{3}$ Budapest University of Technology and Economics, Budapest, Hungary \\ ${ }^{4}$ Loyola Institute of Science and Technology (LoyolaTech), \\ Universidad Loyola Andalucia, Seville, Spain
}

\begin{abstract}
European and global electricity sector decarbonisation is driving changes in wholesale electricity markets as market operators, regulators and system operators encourage increased levels of flexibility. Existing wholesale market design characteristics are changing; new, parallel marketplaces are also emerging. This paper analyses the design space for ancillary services and balancing markets, considers settings in Europe using ENTSO-E annual survey data and discusses changes to market settings that promote flexibility. Finally, it proposes some basic changes to the intraday market.
\end{abstract}

\section{Introduction}

The EU 2030 targets impose a 40\% reduction of greenhouse gas emission (compared to the 1990 levels). As a result, power systems are experiencing major changes to their infrastructure and operation that increase uncertainty at the point of generation and consumption, affecting the behaviour of all power system participants and their interaction with wholesale electricity markets. In addition, new market designs are required for enhancing and increasing the system flexibility.

With respect to the market design, decarbonisation of the power system creates challenges. For instance, it increases the need to procure services and the need to redispatch or use reserves to balance the electricity system after day ahead market or intraday market gate closure. Decarbonisation also creates opportunities, such as in the intraday market, which provides an opportunity to resolve schedule imbalances that remain at the end of the day ahead market.

Within this paper, options for flexibility in different time frames are discussed, followed by analysis of the design space for ancillary services and balancing markets. The paper then considers the market current market settings in ancillary services markets across Europe. 


\section{Market Requirements and Options for Flexiblity}

The optimal design of the market for increasing system flexibility requires the adjustment of certain parameters of wholesale markets to affect the behaviour and performance of those markets. It is possible to analyse the design space of the market, to consider settings within the design space, and to consider which settings have the greatest impact on flexibility.

Different pathways to a more flexible electricity markets are possible. Efficient market design will find market solutions for the dispatch of flexibility, while reducing the need for TSO-procured reserves. Ultimately, market design should enable price signals for investment in the required flexible resources, and it should ensure that all market participants capable of providing flexibility have access to the market.

Market design must also ensure that the market gives price signals for investment in flexibility. This is best achieved in a market that is free of distortion, such as regulated prices, exit barriers, price caps and undue subsidies. Such distortions endanger longterm market functioning by limiting market participants' ability to obtain sufficient remuneration from the market. While such distortions are not the only factor, they have added to the continuous price decline of European wholesale markets in recent years.

Various steps are proposed in the literature to improve market flexibility. For example, market integration helps to reduce net volatility in supply and demand, decreasing the overall need for flexible resources. By nature, peaks and troughs in two geographically separate electricity systems are to some degree decorrelated. The higher the degree of decorrelation, the lower the combined system volatility and the lower the need for flexible resources. In addition, the total capacity of flexible resources necessary to operate the combined system is lower than for a single system. Reserves can therefore be shared, resulting in potential cost reduction.

Scarcity pricing could enable higher remuneration of flexible resources, if price floors and ceilings were removed. More cost-reflective grid charges can lead to systembeneficial decisions by prosumers. Higher temporal resolution of energy-only market prices can decrease the need for balancing activities of grid operators. At retail level, dynamic pricing and/or aggregation would be a prerequisite for demand participation. Higher geographical resolution of prices as well as grid-adapted price zones could better reflect grid constraints and give a price signal for grid-adaptive investment.

In the next section, the design space for ancillary services, balancing markets, and intraday markets is considered and analysed separately.

\section{Flexibility in Ancillary Services Markets}

\subsection{Market Design Space}

There are many local differences between European member states when it comes to implementation of ancillary services. The ENTSO-E annual survey on Ancillary Services Procurement and Electricity Balancing Market Design [1] is used to characterise 
the design space for implementation of ancillary services. The survey is used to monitor the implementation of the European guideline on electricity balancing and to report on the development towards a European balancing market. The survey has been conducted since 2013; the 2017 survey included results from: Austria, Belgium, Bosnia \& Herzegovina, Croatia, Czech Republic, Denmark, Estonia, Finland, France, Germany, Greece, Hungary, Ireland \& Northern Ireland, Italy, Latvia, Lithuania, Holland, Norway, Poland, Portugal, Romania, Serbia, Slovakia, Slovenia, Spain, Sweden, Switzerland, and the United Kingdom (Table 1).

Table 1. Requirements for flexibility in different time frames

\begin{tabular}{|c|c|c|}
\hline Market/timeframe & Characteristics & $\begin{array}{l}\text { Requirements for flexibility in } \\
\text { this timeframe }\end{array}$ \\
\hline $\begin{array}{l}\text { Balancing/ancillary } \\
\text { services }\end{array}$ & $\begin{array}{l}\text { - Covers short term un-expected } \\
\text { or unresolved imbalances } \\
\text { - Managed by SO } \\
\text { - Affected by gate closure time of } \\
\text { medium term markets } \\
\text { - Includes forward contractual } \\
\text { certainty regarding payments - } \\
\text { services often include availability } \\
\text { fees }\end{array}$ & $\begin{array}{l}\text { - Fast reaction time (typically } \\
\text { less than } 5 \text { min) } \\
\text { - High ramping requirements - } \\
\text { speed of variability critical } \\
\text { - Low ramping costs } \\
\text { - Low dispatch costs } \\
\text { - Can be automated based on pre- } \\
\text { agreed parameters and contracts } \\
\text { - Can operate in short duration - } \\
\text { in EU typically up to } 1 \mathrm{~h} \\
\text { - Able to be part of phased } \\
\text { response to a system disturbance } \\
\text { within clearly defined parameters } \\
\text { (typically based around primary, } \\
\text { secondary, tertiary response) }\end{array}$ \\
\hline $\begin{array}{l}\text { Day ahead and } \\
\text { intraday markets }\end{array}$ & $\begin{array}{l}\text { - Defined by various products, } \\
\text { trading options } \\
\text { - Impact on RES/load affected by } \\
\text { gate closure times } \\
\text { - Increased liquidity reduces } \\
\text { reliance on balancing energy } \\
\text { requirements } \\
\text { - Trading in IDM/DAM results in } \\
\text { revenue only associated with the } \\
\text { trade - no long term certainty on } \\
\text { revenue beyond historical } \\
\text { performance } \\
\text { - Participation limited by market } \\
\text { settings related to bid size and } \\
\text { minimum duration }\end{array}$ & $\begin{array}{l}\text { - Predictability - must be able to } \\
\text { commit to schedule requirements } \\
\text { - Reaction time and ramping } \\
\text { requirements governed by gate } \\
\text { closure - normally } 1 \mathrm{~h} \text { in EU } \\
\text { - Headroom/footroom that allows } \\
\text { alteration in committed energy } \\
\text { close to real time } \\
\text { - Ramping and start up costs are } \\
\text { relevant but only if variability } \\
\text { forces change in operating } \\
\text { characteristics in a timeframe that } \\
\text { incurs additional costs } \\
\text { - Must be able to respond for } \\
\text { minimum duration at a minimum } \\
\text { size - sets lower limit on storage } \\
\text { or DSR participation, for example }\end{array}$ \\
\hline
\end{tabular}


In general, the survey tries to align to the standardised ENTSO definitions for ancillary services, these being: frequency containment reserve (FCR), automatically activated reserve through frequency restoration reserve capacity and energy (aFRR$\mathrm{C} / \mathrm{E}$, previously named regulating power or secondary control reserve), manually activated reserve through frequency restoration reserve capacity and energy (mFRR$\mathrm{C} / \mathrm{E}$, previously named reserve power or tertiary control reserve), and replacement reserve capacity and energy $(\mathrm{RR}-\mathrm{C} / \mathrm{E})$.

\subsection{Analysis of Settings in European Markets}

After characterising the design space, the ENTSO-E survey was used to characterise the settings.

First, regarding resolution, there have been some downward changes in resolutions for providing capacity in ancillary service markets: a number of countries have moved towards an hourly resolution for mFRR-C, and overall for mFRR-C there seems to be a shift in resolution from higher to lower resolutions. For mFRR-E there is no noticeable shift in resolution - most countries have not changed settings since 2013, with most countries using an hour. Only France and Ireland have set their resolution at $30 \mathrm{~min}$; and only Spain, Belgium and Holland at 15 min.

There has been a general trend towards lower product resolution - allowing smaller sources/loads to participate in ancillary services markets. However, there is no clear pattern across borders or between different products. Most are already reasonably small - typically 1-5 MW, although some countries have actually increased their minimum bid size, for example Norway, which has increased bid size from 1-5 MW to 5-10 MW for aFRR-C, and Spain, which has increased from now minimum to $>10 \mathrm{MW}$ for aFRR.

Activation time for aFRR-E has changed for a number of countries. France changed from less than 1 min to between $15 \mathrm{~min}$ and $1 \mathrm{~h}$. Belgium and Italy changed from between $15 \mathrm{~min}$ and $1 \mathrm{~h}$ to less than $1 \mathrm{~min}$, and Hungary changed from 5-15 min to less than $1 \mathrm{~min}$.

Regulated pricing for ancillary services is in a minority. Pay as bid is the preferred methodology.

For mFRR-C in 2017 cost recovery was mostly from grid users through a tariff. Only Austria and Serbia recover 100\% from Balance Responsible Parties, although Norway, Sweden, Finland, and Hungary use a hybrid approach. For mFRR-E only Ireland, Germany and Bosnia Herzegovina use cost recovery from grid users. Almost all other European countries use 100\% recovery from BRP (Table 2). 
Table 2. Design space variables for ancillary services markets in Europe

\begin{tabular}{|c|c|}
\hline Design variable & Variable options \\
\hline Procurement scheme & Hybrid, Mandatory only, Market only \\
\hline Product resolution (MW) & Numerical value \\
\hline Product resolution (time) & Hours, days, weeks, months, years \\
\hline $\begin{array}{l}\text { Distance to real time of } \\
\text { auctions }\end{array}$ & Hours, days, weeks, months, years \\
\hline Allowed provider type & $\begin{array}{l}\text { Generators Only, Generators + Load, Generators + Pump } \\
\text { Storage, Generators + Load + Pump Storage, Batteries, } \\
\text { Generators + Load + Batteries, Generators + Load + Pump } \\
\text { Storage + Batteries }\end{array}$ \\
\hline Symmetrical product & $\mathrm{Y} / \mathrm{N}$ \\
\hline Pricing mechanism & Pay as bid, Marginal Pricing, Regulated Price \\
\hline Cost recovery scheme & Grid users, BRP, Hybrid \\
\hline Monitoring & Real-Time Monitoring, Ex-Post Check, Hybrid \\
\hline Transfer allowed & Yes, No, Yes only in case of forced outage \\
\hline $\begin{array}{l}\text { Transfer with secondary } \\
\text { market }\end{array}$ & Yes, No \\
\hline Settlement rules & Pay as bid, Marginal Pricing, Regulated Price, Hybrid \\
\hline Activation rule & Pro-rata (parallel activation), merit order \\
\hline Activation time & Time \\
\hline Partial activation & $\begin{array}{l}\text { Yes, in all directions; No in none direction; Only in upward } \\
\text { direction; Only in downward direction }\end{array}$ \\
\hline Load specific rules & $\begin{array}{l}\text { Long term contracts TSO-BSP; Long term auctions; Short term } \\
\text { auctions; Specific market solution }\end{array}$ \\
\hline $\begin{array}{l}\text { TSO control - load } \\
\text { participation }\end{array}$ & $\begin{array}{l}\text { No Control; Direct Control (Automatic); Direct Control } \\
\text { (Manual); Relay }\end{array}$ \\
\hline
\end{tabular}

In ancillary services markets there have been changes made to allow load and battery participation, with the greatest change being apparent in FCR. Holland and Switzerland have been the most progressive in allowing batteries to participate in ancillary services, but only Switzerland has opened up all markets to batteries. In aFRR and RR the options for batteries are much more limited. Batteries have emerged as allowed participants in FCR-C since 2013 and are now permitted in FCR-C in Finland, Denmark, Holland, Northern Ireland, Ireland, Great Britain, France Switzerland and Germany. The precursor appears to have been the participation of pumped storage in the FCR-C market: all of the countries mentioned already allowed pumped storage in the FCR-C market except Holland and France. Either could be a model for a transition in other countries. For mFRR-C only Great Britain and Switzerland allow batteries, and for RR-C only Switzerland allows batteries.

Load participation is widely accepted for mFRR, but is less common for aFRR. For aFRR-E load was allowed previously in Finland, Denmark and Germany, and is now possible in addition in Belgium, Holland, Austria, and the Czech Republic. Most 
countries still only allow generation. This may be due to control requirements or settings required for aFRR.

For mFRR-C load was previously allowed in France, Denmark, Slovenia, Hungary, Norway, Great Britain, Germany, Sweden, Finland and Holland. Now load participation is also possible in Belgium, Austria, Slovakia, Ireland, Northern Ireland, and Bosnia and Herzegovina. For mFRR-C, markets allowing access by generators only are in a minority. Load participation is only allowed in a small number of countries for RR. This may be due to the long duration of RR - it can extend for days, making disconnection of load impractical. The requirements for RR are also heavily dominated by generator-only rules.

It should be mentioned that although there are available technologies to provide ancillary services such as inertia and spinning reserve emulation, primary voltage and frequency regulation, there are as yet not many products that could specifically be designed for such services. Where consideration of these services can increase flexibility in power systems, they require updates on the current market platforms.

\subsection{Possible Changes: Ancillary Services Markets}

First, settings relating to the TSO, and the role of the TSO itself, are important considerations. Service providers should be able to compete with any TSO assets providing system services on an equal footing. A minimum requirement is to increase transparency on the system, including information on cost levels of TSO assets and market participant compensation when they are providing the same services as TSO assets. Article 54 [2] of the proposal for the Electricity Directive states that TSOs shall not be allowed to own, manage or operate energy storage facilities and shall not own directly or indirectly assets that provide system services. It does leave room for derogations for individual countries based on a set of conditions. If derogations are made, they should be on the basis of a level playing field between TSOs and market participants providing the same services. If a power plant can provide the same service more cost-effectively, then consideration should be given to whether it is used instead of the TSO assets. The system needs and cost of providing services by TSO assets should be transparent to reduce information asymmetry between TSOs and market participants. Furthermore, the use of TSO assets should be transparent and provide a price signal and remuneration to market participants providing the same service. In addition, the TSOs should perform an assessment, at regular intervals, of the potential interest of market parties to own the assets in case they can provide the service in a cost-effective manner as also mentioned in the Directive.

Second, marginal pricing for all balancing services, energy and capacity, ensures that service providers receive the full marginal value of the service they are providing. Pay-as-clear pricing is used already in the most relevant market for balancing energy. Pay-as-bid may be justified if there is flexibility in the product definitions formally or in practice, in which case the practice of doing this should be made transparent to all service providers. Marginal pricing should be considered as a more transparent approach for procuring services in ancillary services markets. 


\section{Flexibility in Balancing Markets}

\subsection{Market Design Space}

There are various approaches defined in the literature that define the design space for the balancing market, and ways to measure flexibility in this timeframe, for example [3-7]. The U.S. Department of Energy Grid Modernisation Laboratory [8] proposes the list of values within Table 3 - Column A as metrics for measuring flexibility in balancing markets. Within the EU, Van der Veen (2016) proposed criteria for measuring the effectiveness of balancing markets, broken down according to security of supply, economic efficiency, market facilitation and multinational criteria. The metrics are summarised in Table 3 - Column B. The metrics are aligned to objectives stated in the ACER Framework Guidelines (2012), which were adopted as regulations during 2015-2017, and were reinforced by a survey conducted amongst balancing market experts. The ACER guidelines on energy balancing propose the criteria described in Table 3 - Column C.

Table 3. Comparison of metrics for measuring effectiveness of balancing market

\begin{tabular}{|c|c|c|}
\hline Colum A & Column B & Column C \\
\hline $\begin{array}{l}\text { U.S. Department of Energy Grid } \\
\text { Modernisation Laboratory }\end{array}$ & Van der Veen (2012) & ACER \\
\hline $\begin{array}{l}\text { 1. Loss of load } \\
\text { 2. Insufficient ramping } \\
\text { 3. Flexibility ratio } \\
\text { 4. Wind generation } \\
\text { 5. Solar generation fraction } \\
\text { 6. Wind generation volatility } \\
\text { 7. Solar generation volatility } \\
\text { 8. Net load forecasting error } \\
\text { 9. Net load factor } \\
\text { 10. Maximum ramp rate in net load } \\
\text { 11. Maximum ramp capacity } \\
\text { 12. Energy storage available } \\
\text { 13. Demand response capability } \\
\text { 14. Inter-regional transfer capability } \\
\text { 15. Intra-regional transfer capability } \\
\text { 16. Interruptible tariffs } \\
\text { 17. Renewable curtailment } \\
\text { 18. Negative LMP } \\
\text { 19. Price spikes } \\
\text { 20. Load shedding } \\
\text { 21. Operational reserve shortage } \\
\text { 22. Control performance (CPSs } 1.2 \text {; } \\
\text { BAAL) } \\
\text { 23. Out-of-market operations }\end{array}$ & $\begin{array}{l}\text { 1. Security of supply } \\
\text { criteria } \\
\begin{array}{l}\text { 1.1. Availability of } \\
\text { balancing resources }\end{array} \\
\text { 1.2. Balance planning } \\
\text { accuracy } \\
\text { 1.3. Balance quality } \\
\text { 2. Economic efficiency } \\
\text { criteria } \\
\text { 2.1. Cost allocation } \\
\quad \text { efficiency } \\
\text { 2.2. Utilisation efficiency } \\
\text { 2.3. Price efficiency } \\
\text { 2.4. Operational } \\
\quad \text { efficiency } \\
\text { 3. Market facilitation } \\
\text { criteria } \\
\text { 3.1. Transparency } \\
\text { 3.2. Non-discrimination } \\
\text { 4. Multinational criteria } \\
\text { 5. Internationalisation costs } \\
\text { 6. Social welfare of cross- } \\
\text { border exchanges }\end{array}$ & $\begin{array}{l}\text { (a) availability of } \\
\text { balancing resources } \\
\text { (reserves, availability } \\
\text { distribution); } \\
\text { (b) total costs of } \\
\text { balancing (balancing } \\
\text { energy price distribution, } \\
\text { activated balancing } \\
\text { energy, procurement of } \\
\text { reserves); } \\
\text { (c) quality of balancing } \\
\text { (e.g. Area control error } \\
\text { open loop, area control } \\
\text { error, unintentional } \\
\text { deviations); } \\
\text { (d) welfare gain due to } \\
\text { cross-border exchanges } \\
\text { of balancing energy and } \\
\text { reserves }\end{array}$ \\
\hline
\end{tabular}




\subsection{Possible Changes: Balancing Markets}

First, considering steps that are taken to increase price sensitivity to scarcity: the main challenge with sharper scarcity prices is that they increase the price risks for BRPs if there are no tools to hedge their position. In particular, high volatility is more difficult for smaller and non-portfolio market players which can be more exposed to individual price spikes. Moving to single-price imbalance settlement helps to mitigate this issue as market participants can then create instruments to hedge themselves against imbalance price spikes.

Second, considering load curtailment: in the event of involuntary load curtailments, any lost load could be estimated and included in the imbalance positions of individual BRPs and the calculation of the system imbalance volume and the marginal imbalance price.

Third, it may be beneficial to remove the condition that the day-ahead price sets the floor for the up-regulation price and the cap for the down regulation price, and consequently for imbalance prices (except as a backstop price in the event that there are no balancing trades, and if an intraday price cannot be used). Linking the balancing and imbalance prices with the day-ahead prices sets a restriction on free price formation. As updated information is received on e.g. wind forecasts, the situation can change so that the marginal cost to produce energy for up-regulation can be cheaper than it was in the day-ahead stage. Removing this link can lead to situations where the imbalance price is lower than the day-ahead even during up-regulation settlement periods and might provide incentives for market participants to speculate against the imbalance prices. In the long run, free price formation should however lead to the most efficient market outcomes and is in the philosophy of the energy only market.

Fourth, it could be beneficial to remove balancing obligations at the day-ahead and any other stage, better allowing the market to support system balancing. Given the increasing share of fluctuating electricity generation, a rule stipulating that balance must be ensured $12-36 \mathrm{~h}$ prior to the hour of operation is contrary to the inherent characteristics of the market. Any balancing obligations at the day-ahead stage, or any other stage, could be removed.

Fifth, better access to information on system imbalance and balancing and imbalance prices in real-time would support market operation. Balancing activations and prices should be published as close to real-time as possible, which serves as an indication for imbalance prices to guide behavior of market participants, allowing them to react in real-time (demand) or submit balancing bids for the next imbalance settlement period (generation). Publishing bid curves could be considered as an additional way to improve transparency, but it requires further analysis.

Sixth, the gate closure to submit bids to the Regulating Power Market should be moved as close to the operating hour as possible. Trading closer to the hour of operation can reduce the forecasting errors by the market participants and contribute to balancing the electricity system as a whole. On the other hand, the closer trading occurs to the delivery hour, the less time there is for TSOs to plan their balancing actions to respond to imbalances and grid congestions.

Lastly, reducing minimum bid size supports new entrants and new behavior, especially from demand-side and other distributed resources such as storage and smallscale generation. The new resources which could emerge would be different in nature 
to the existing resources. This might require a revision of current requirements to access the balancing market to make sure the requirements are fit for purpose and not overly restrictive towards smaller scale resources. On the other hand, an adequate level of system security needs to be guaranteed and there needs to be a level playing field for different types of resources, e.g. same prequalification process.

\section{Flexibility in Intraday Markets}

\subsection{Proposed Changes: Intraday Markets}

In the same manner as in the balancing market some proposed changes can be performed in the intraday market for enhancing system flexibility.

Intraday auctions, first, have proven successful in a number of markets across Europe. Possible settings include market time units for the intraday as close as practically possible to the setting of day-ahead prices and recalculation of available capacities; 15-min products; continuous trading from the resolution of the opening auction until the gate closure time of the ID market; and the possibility of combining with a closing auction in addition to the opening auction. Continuous trading could solve the need of companies with weather-dependent generation or demand, as well as during capacity failures. Extra auctions in addition to an opening auction would be required if there is a relevant market related event that occurs every day. With a largescale release of reserved capacity, for instance, a further auction could be warranted.

Second, the market would benefit from gate closure time (GCT) as close to realtime as possible. The regional cross-zone intraday GCT should be as close to the operating hour as possible. Shortening the GCT for ID trading should ideally be accompanied with change to the deadline for submitting production plans.

Again, information transparency between market participants and TSOs is important. As market participants trade closer to real time, greater transparency is needed. Market participants should provide the TSO with detailed, up to date information. TSOs should provide up to date, consolidated data on the overall system position. For market participants, this could consist of preliminary and final production plans on a unit level above a certain size limit. This allows the market participants to take better informed decisions on their balance portfolios and the TSOs to prepare for their actions during the balancing timeframe.

Fourth, price cap setting in the intraday market should be set to better reflect the value of lost load.

Fifth, allocation of cross-zone capacity across market timeframes through an explicit cross-zone capacity product could be beneficial to allocate cross-zone capacity across market timeframes, opening up intraday trading between price zones.

Due to increase in distributed generation including renewable resources, reverse power flows in the system can cause technical challenges. These technical challenges can in return affect the prices directly. As a result, possible factors (e.g. penalty) might ensure the limit on the market that is linked to the operation (similar to price cap).

Another point to address this issue could be a consideration of local markets. This could bring higher efficiency in the pricing as not all regions in the system may require the same level of flexibility and reserve. Hence, local flexibility markets could offer 
local services to overcome the system level challenges. However, remuneration for such services would require further investigations.

\section{Conclusions}

This paper reviews ancillary, balancing market and intraday settings in Europe. It identifies the bottlenecks and provides a number of proposals for each on how further developments of these markets could provide higher level of flexibility for the power system. The Flexitranstore project, will use simulations and further analysis to assess the viability and impact of these proposals. It will also further develop a definition of the intraday market design space and possible changes to market settings within it.

Acknowledgments. This article was produced as part of the FLEXITRANSTORE project. The FLEXITRANSTORE project has received funding from the European Union's Horizon 2020 research and innovation program under Grant Agreement No. 774407.

\section{References}

1. ENTSO-E Market Survey 2017. https://www.entsoe.eu/publications/market-reports/\#pastsurveys. Accessed September 2018

2. Directive 2003/54/EC of the European Parliament and of the Council of 26 June 2003 concerning common rules for the internal market in electricity and repealing Directive 96/92/EC

3. Riesz, J., Milligan, M.: Designing electricity markets for a high penetration of variable renewables. Wiley Interdiscip. Rev. Energy Environ. 4, 279-289 (2014)

4. Developing Balancing Systems to Facilitate the Achievement of Renewable Energy Goals, Position Paper, ENTSO-E (2011)

5. Survey on Ancillary Services Procurement and Balancing Market Design, ENTSO-E (2014)

6. Rebours, Y., Kirschen, D., Trotignon, M.: Fundamental design issues in markets for ancillary services

7. Stoft: 2002 Power System Economics - Designing Markets for Electricity

8. https://www.energy.gov/grid-modernization-initiative-0/grid-modernization-lab-consortium

Open Access This chapter is licensed under the terms of the Creative Commons Attribution 4.0 International License (http://creativecommons.org/licenses/by/4.0/), which permits use, sharing, adaptation, distribution and reproduction in any medium or format, as long as you give appropriate credit to the original author(s) and the source, provide a link to the Creative Commons license and indicate if changes were made.

The images or other third party material in this chapter are included in the chapter's Creative Commons license, unless indicated otherwise in a credit line to the material. If material is not included in the chapter's Creative Commons license and your intended use is not permitted by statutory regulation or exceeds the permitted use, you will need to obtain permission directly from the copyright holder.

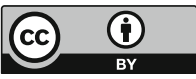

